\title{
Cadeira para parto de cócoras: A influência da ergonomia na experiência do parto humanizado
}

\author{
Chair for squatting: The influence of ergonomics on the experience of \\ humanized childbirth
}

\author{
CAVALCANTI, Anna Sylvia Ramos de Rangel Moreira; Doutora; UniFAVIP \\ cavalcantiannas@gmail.com \\ ROSA, Maria Eduarda Ramos Cavalcanti; Mestre; UFAL \\ dudah.cavalcanti@gmail.com
}

\section{Resumo}

A usabilidade do sistema de trabalho depende de todos os fatores que podem influenciar o uso de um produto, incluindo fatores organizacionais, localização e aparência do produto, além das diferenças dos indivíduos. Eficiência, eficácia e satisfação são ferramentas necessárias na elaboração de produtos ergonômicos, sendo os métodos, normas e análises, importantes para seu bom desempenho. Considerando a crescente humanização do parto e os fatores que podem contribuir para a elaboração de um produto mais adequado às demandas contemporâneas da mulher, desenvolveu-se uma cadeira para parto de cócoras, que facilita o trabalho de parto e diminuí as intervenções cirúrgicas. Foi possível ver a importância da ergonomia para o produto centrado no usuário, promovendo melhorias para os profissionais da saúde e gestantes, impactando na melhor prestação de serviço à população.

Palavras Chave: cadeira; parto de cócoras; ergonomia e design.

\begin{abstract}
The usability of the work system depends on all the factors that can influence the use of a product, including organizational factors, location and appearance of the product, besides the differences of individuals. Efficiency, efficacy and satisfaction are necessary tools in the elaboration of ergonomic products, being the methods, norms and analyses, important for its good performance. Considering the increasing humanization of childbirth and the factors that can contribute to the elaboration of a product more suitable to the contemporary demands of women, a chair was developed for squatting, which facilitates labor and decreases the surgical interventions. It was possible to see the importance of ergonomics for the user-centric product, promoting improvements for health professionals and pregnant women, impacting on the best rendering of service to the population.
\end{abstract}

Keywords: chair; squatting; ergonomics and design. 


\section{O Parto e sua Humanização}

A gravidez é uma experiência universal como condição para a existência da humanidade. É um período responsável por modificações no corpo da mulher, que dura cerca de nove meses até o nascimento.

A obstetrícia contemporânea tem contribuído para melhorar a saúde das mulheres e crianças, principalmente aquelas que passam por uma gestação difícil. Porém, esse sistema de atendimento centrado no médico também trouxe alguns efeitos negativos, como: o excesso de intervenções médicas, o uso de drogas e alto índice de procura pelo parto cesariano, cirurgia de médio porte, que pode apresentar complicações mais frequentes que no parto normal (CARVALHO et al., 1996).

$\mathrm{Na}$ antiguidade, existiam certas tradições em acompanhar a gestação, sendo essa prática eminentemente feminina, que foram chamadas de parteiras. Estas eram responsáveis em acompanhar desde a fase inicial da gestação até o período expulsivo, fase que a parturiente atinge uma dilatação completa. As parteiras procuravam posições para um parto mais fácil, seguro e confortável, tanto para as parturientes quanto para o bebê (SILVA, 2004).

Nos povos Incas e Astecas, os partos procediam na posição de cócoras (SILVA, 2004). No Brasil, os partos que adotavam essa posição, ocorriam principalmente nas tribos Guarani e Kaigangue (ACKER et al., 2006). Entretanto, com a evolução social, a diferenciação dos povos pela riqueza, indústria, vida mais fácil e mais cômoda, as mulheres foram mudando seus comportamentos e hábitos, e com essas mudanças surgiu o enfraquecimento em relação a sua estrutura física. Também por esta razão, apareceram as dificuldades em manter a posição primitiva do parto.

A partir dessas transformações surgem as primeiras referências de cadeiras obstétricas, inventadas pelos egípcios. Estas primeiras referências foram usadas frequentemente pelos gregos, onde as mulheres pariam sentadas ou reclinadas, como apresenta a figura 1 (MARINHO 2004).

Figura 1 - Cadeiras para parto sentadas ou reclinadas na antiguidade.

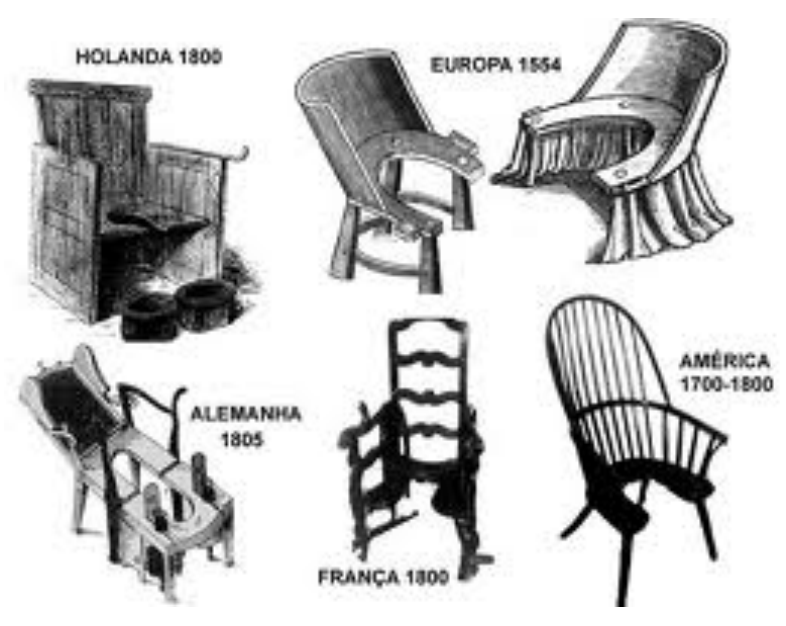

Fonte: Núcleo Bem Nascer (2001)

A partir de 1700, o médico francês Francisco Mauriceau começou a executar uma nova 
manobra obstétrica, a posição dorsal, que virou corriqueira na Europa, pois proporcionava status, e até hoje é usada por muitos médicos. Essa posição foi adotada na prática médica devido ao apelo psicológico de que o médico deve estar numa posição superior ao paciente. Logo, influenciados por métodos e condutas européias, o Brasil, passou a adotar esta nova manobra, submetendo-se ao decúbito dorsal (LIMA, 2006).

Segundo LANCET (2006), dentre os fatores negativos da cesariana, pode-se citar o estresse e a tensão gerada pela hospitalização, além da perda da consciência durante o nascimento, associado à frustração da sua incapacidade de parir por via vaginal. Além disso, a cesariana sem indicação tem maior índice de mortalidade maternal (20\%) e neonatal, aumento de infecção puerperal e uso de antibióticos, aumento das admissões em UTI neonatal e aumento do parto prematuro.

Segundo Duarte (2004), o parto de cócoras é mais rápido, oxigena melhor o bebê, as mulheres sentem mais controle da situação, tem participação mais ativa do companheiro, há redução considerável no uso da episiotomia, entre outros benefícios. Para Gardenal (2003), as crianças que nascem através do parto de cócoras são mais saudáveis. Consoante a isso, em 1970, Moyses Paciornik estudou comunidades indígenas e resgatou o parto verticalizado. Junto com seu filho Dr. Cláudio Paciornik, desenvolveram uma cadeira (figura 2) que auxilia o parto na posição de cócoras, e tem conquistado mais espaço com as parturientes que optam pelo parto natural.

Figura 2: Cadeira criada e patenteada por Cláudio Paciornik (1970)

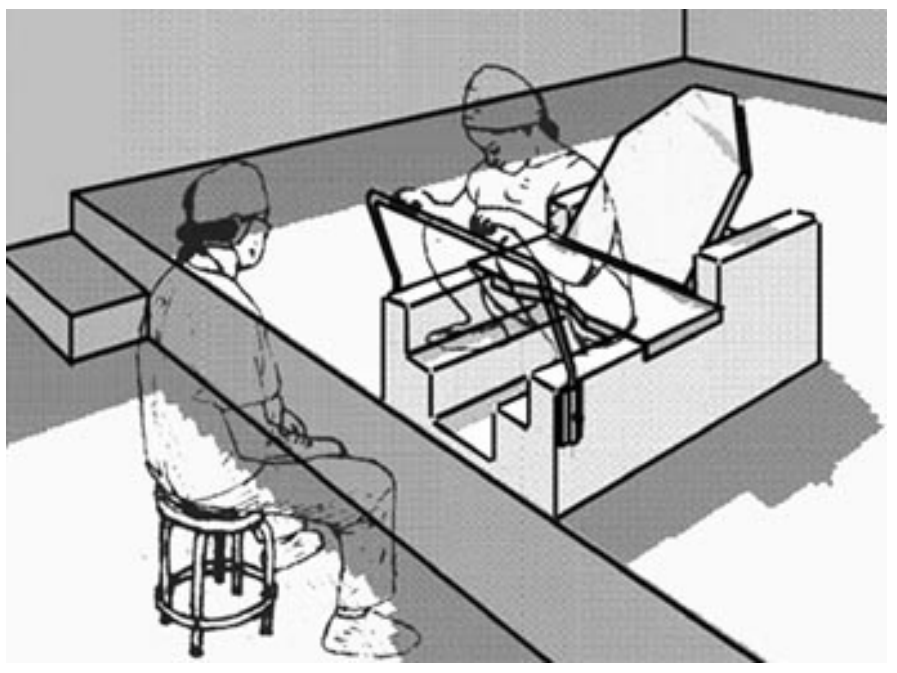

Fonte: Núcleo Bem Nascer (2001)

Pesquisas direcionadas têm despertado no Ministério da Saúde programas de reciclagem médica, para treinar os profissionais do Sistema Único de Saúde para o parto normal. As universidades, a partir de 2010, também foram obrigadas a garantir treinamento em parto normal para os médicos em formação, dando as parturientes o direito de gestar e parir com uma atenção humanizada e qualificada.

A partir desse regaste, surge um novo espaço para trabalhar com parto humanizado, e consequentemente, um campo para obtenção de produtos que auxiliem esse tipo de atividade. 


\section{A Importância da Ergonomia no Desenvolvimento de Produtos}

A ergonomia é derivada das palavras gregas ergon (trabalho) e nomos (regras), e trata-se de um estudo sobre a adaptação do trabalho ao homem. Segundo lida (2005):

"A ergonomia é o estudo das interações das pessoas com a tecnologia, a organização e o ambiente, objetivando intervenções e produtos que visem melhorar, de forma integrada e não dissociada, a segurança, o conforto, o bem-estar e a eficácia das atividades humanas" (IIDA, 2005).

Existem evidências substanciais e convincentes que a aplicação da ergonomia aos produtos de consumo melhora algumas características dos mesmos, tais como: a facilidade do uso, habilidade de aprendizagem, eficiência, conforto, segurança, adaptabilidade e satisfação do usuário (KARWOWSKI; SOARES; STANTON, 2011).

O designer usufrui dos conhecimentos da ergonomia para o desenvolvimento de projetos e produtos, buscando melhor interação com o usuário. Segundo Adul e colaboradores (2004), os estudos ergonômicos ajudam a solucionar diversos problemas relacionados à saúde, segurança, conforto e eficiência e contribuem para a prevenção de erros (ADUL; WEERDMEESTER, 2004).

PHEASANT (1995) argumenta que os designers precisam ter em mente que a ergonomia não é apenas a aplicação de dados, e sim desenvolver uma abordagem totalmente centrada no usuário. O design centrado no usuário é um método para desenvolver produtos baseados nas necessidades e interesses dos usuários, com ênfase em tornar o produto útil e compreensível.

O grande desafio da ergonomia é compreender a interação entre o ser humano e tudo que o rodeia. Com base neste conhecimento, a ergonomia busca otimizar o bem estar do usuário e um melhor desempenho de todo o sistema e do meio que ele está inserido. Neste contexto, para o desenvolvimento de produtos, não há como desconsiderar os condicionantes e resultantes de tudo que interfere nessa interação produto-usuário-ambiente.

A ergonomia ocupa-se não só da relação do homem com o objeto, mas também do homem com o ambiente onde está inserido, sendo A Ergonomia do Ambiente Construído - EAC, um segmento que amplia seu olhar para o ambiente e os objetos, e considera, além do usuário, a tarefa realizada. A EAC não deve ocupar-se apenas de quem irá usá-la, mas principalmente de onde será utilizada, sendo assim, o ambiente de destinação deve ser analisado como lugar físico e sócio cultural que facilita a interação entre o homem e o objeto (MORAES, 2004).

No contexto das cadeiras para partos humanizados, torna-se relevante avaliar o ambiente hospitalar e a fragilidade física e emocional da paciente, bem como a urgência em reduzir o índice de infecção hospitalar. Além das ações de prevenção e controle que cada profissional faz no exercício de suas atividades, também deve observar as condições que predispõem ao risco das infecções, como por exemplo, a importância de se adquirir equipamentos que contribuam para o êxito desse controle, através da substituição de equipamentos com fácil assepsia.

A ergonomia apresenta como domínios de especialização: a ergonomia física, cognitiva ou organizacional. A ergonomia física trata da relação das características anatômicas, antropométricas, 
fisiológicas e biomecânicas do homem com a atividade física realizada, envolvendo, por exemplo, o estudo do posto de trabalho, posturas, alcances, distúrbios, entre outros (IIDA, 2005).

Já a ergonomia cognitiva compreende os processos mentais (percepção, memória, raciocínio) nas interações do homem com os elementos de um sistema, envolvendo o estudo das cargas de trabalho, estresse, desempenho, entre outros. A ergonomia organizacional busca a melhoria do sistema como um todo (estrutural, política e processual), incluindo o estudo das comunicações, cooperatividade, participação, gestão da qualidade, entre outros (ABERGO, 2013).

A atuação da ergonomia na área da saúde pode ser denominada de Ergonomia Hospitalar que, mesmo pouco difundida, apresenta pesquisas significativas na área de equipamentos médicos e procedimentos. Portanto, a ergonomia e a usabilidade são consideradas fontes ricas de conceitos e métodos que permitem a concepção ou a correção de projetos de forma harmoniosa com o sistema de saúde (CARDOSO, 1998; SERRANHEIRA, 2010).

Segundo Cybis e colaboradores (2010), quando a qualidade de usabilidade não se dá de maneira adequada, podem ser corrigidas, admitindo o benefício no contexto futuro de uso. Para tais modificações são observadas determinadas circunstâncias, que compromete a qualidade da tarefa ou mesmo a inviabilidade da sua realização. Como consequência, pretende-se minimizar constrangimento, má compreensão, traumas, dentre outros fatores, na relação usuário-produto ou usuário-sistema interativo (CYBIS, BETIOL, FAUST, 2010, p. 203).

\section{Cadeira COCH: Um Produto Centrado no Usuário e na Usabilidade}

Segundo a Norma ISO 9241, a qualidade da usabilidade em ergonomia favorece a produtividade confortável, liga-se ao prazer usual do sistema e fornece o bem-estar, saúde e segurança do usuário. Sendo assim, é um forte pilar da ergonomia, senão o principal, uma vez que transmite e proporciona a eficácia, eficiência e satisfação do homem frente ao uso de produtos em suas tarefas (ABNT, 2011).

Levando em consideração os princípios de usabilidade, a cadeira no processo do parto humanizado é importante para o melhor apoio do corpo da mulher. Se o parto for realizado na posição de cócoras, a parturiente pode sofrer desconforto com a pressão na região do joelho, tendo em vista que é um local onde a gestante exerce esforço maior, onde concentra-se seu peso e por consequência, o peso da criança (OLIVEIRA, 2008).

Atualmente, a maioria das cadeiras obstétricas permitem que as mulheres no período expulsivo permaneçam apenas em posição dorsal (deitada), sentada ou semi-sentada. Uma vez que a parturiente fica na posição sentada, deixando os pés e os braços livres, pode dispersar a concentração da força abdominal que precisa ser exercida, e proporciona a realização da força em outras áreas, dificultando o parto.

A posição de cócoras faculta uma maior concentração da força no abdômen, entretanto, necessita de sistemas que proporcionem um melhor apoio aos pés, braços e mãos, tendo em vista que os partos naturais podem durar de seis a doze horas. A partir da iniciativa do resgate do parto vertical foi desenvolvida uma cadeira específica para o parto de cócoras, potencializando a posição. Considerando que às demais patentes se referem as cadeiras que a parturiente permanece em uma posição semi-sentada ou sentada, não estabelece com a usuária uma relação de satisfação e 
eficiência (figura 3).

Figura 3: Cadeira $\mathrm{COCH}$, criada e patenteada pela autora

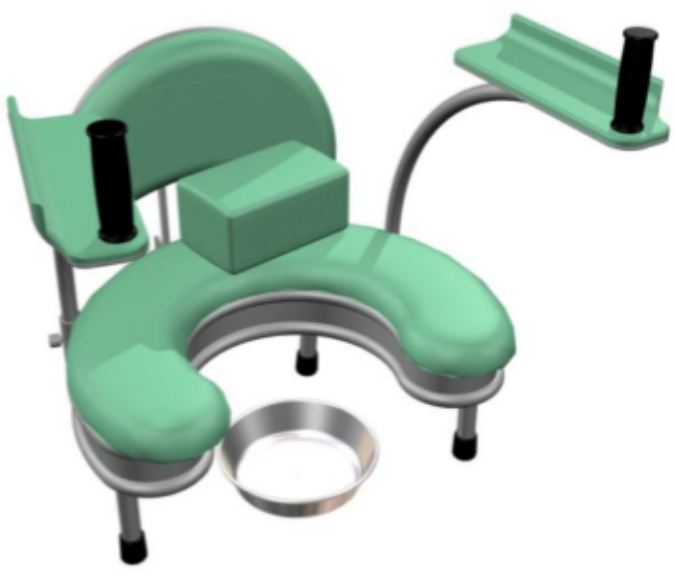

Fonte: autoral (2007)

Segundo Gomes Filho (2010), os problemas ergonômicos, sobretudo, são aqueles que contribuem ou trazem dificuldades aos usuários quanto à utilização do produto. No quesito conforto, os problemas estão associados às condições ou situações de uso dos objetos que possam provocar diversos tipos de fadiga, doenças e constrangimentos no organismo humano (GOMES FILHO, João, 2010, p. 28).

Com o intuito de solucionar vários inconvenientes encontrados nos modelos tradicionais, se desenvolveu a cadeira $\mathrm{COCH}$, cuja principal inovação é um mecanismo para acomodar a gestante de forma que esta tenha apoio para braços e pés. Assim como a versatilidade de ter um espaço destinado ao acompanhante da parturiente e possibilidade de outras posições, incluindo a posição deitada após o nascimento do bebê, seja para descanso ou eventual necessidade de sutura.

Observando os produtos similares, como as banquetas para parto (figura 4), percebe-se que a maioria não possui apoio para braços e/ou pés, que por sua vez, auxiliem na concentração da força para a atividade de expulsão do bebê. As cadeiras existentes também não possuem espaço para que o acompanhante da parturiente assista o parto de forma a interagir com a mesma, sendo este um suporte necessário do ponto de vista psicológico para a parturiente (figura 5). Nesse aspecto devese considerar que a ergonomia não se trata apenas dos domínios físicos e anatômicos para a satisfação do usuário, sendo de extrema importância o bem estar psicológico do indivíduo para a realização da tarefa (ABERGO, 2013). 


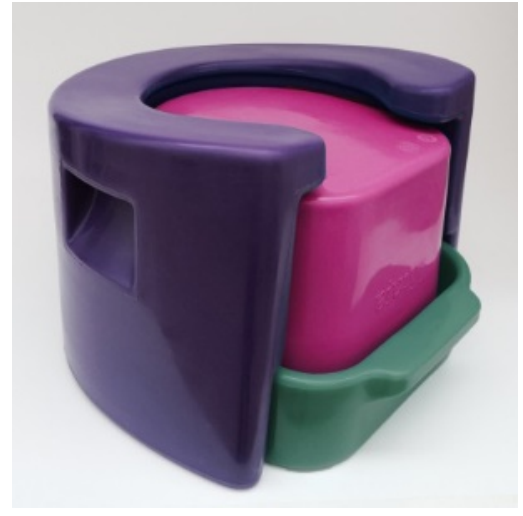

Fonte: www.ilithia.com.br (2013)

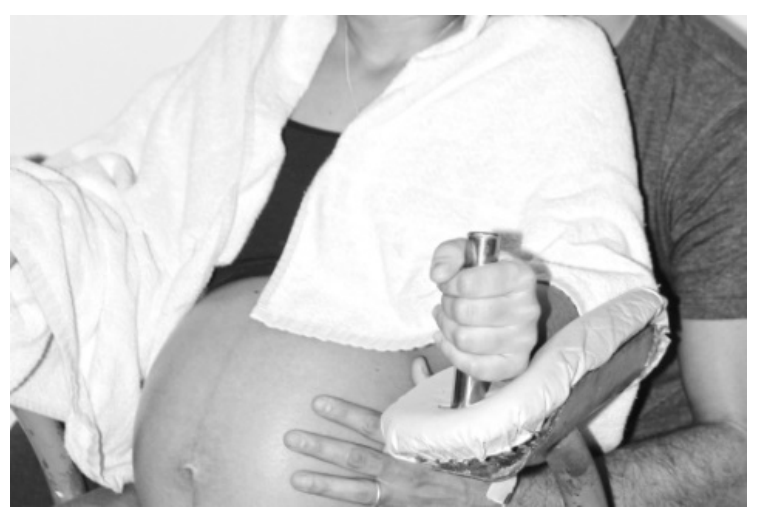

Fonte: autoral (2015)

Além disso, nos produtos existentes no mercado não possui uma articulação que possibilita a gestante fazer o parto dorsal (deitada) ou vertical, de acordo com a demanda que cada situação propõe. No entanto, a cadeira projetada há tal articulação como diferencial, permitindo que o encosto sirva de assento para o acompanhante da parturiente (figuras 6 e 7). Também exerce a função de encosto dorsal ou vertical para a paciente, permitindo maior acessibilidade às diferentes situações e demandas, de acordo com cada gestante e às suas medidas antropométricas.

Figuras 6 e 7: Articulação do encosto permitindo que sirva de assento ou encosto dorsal.
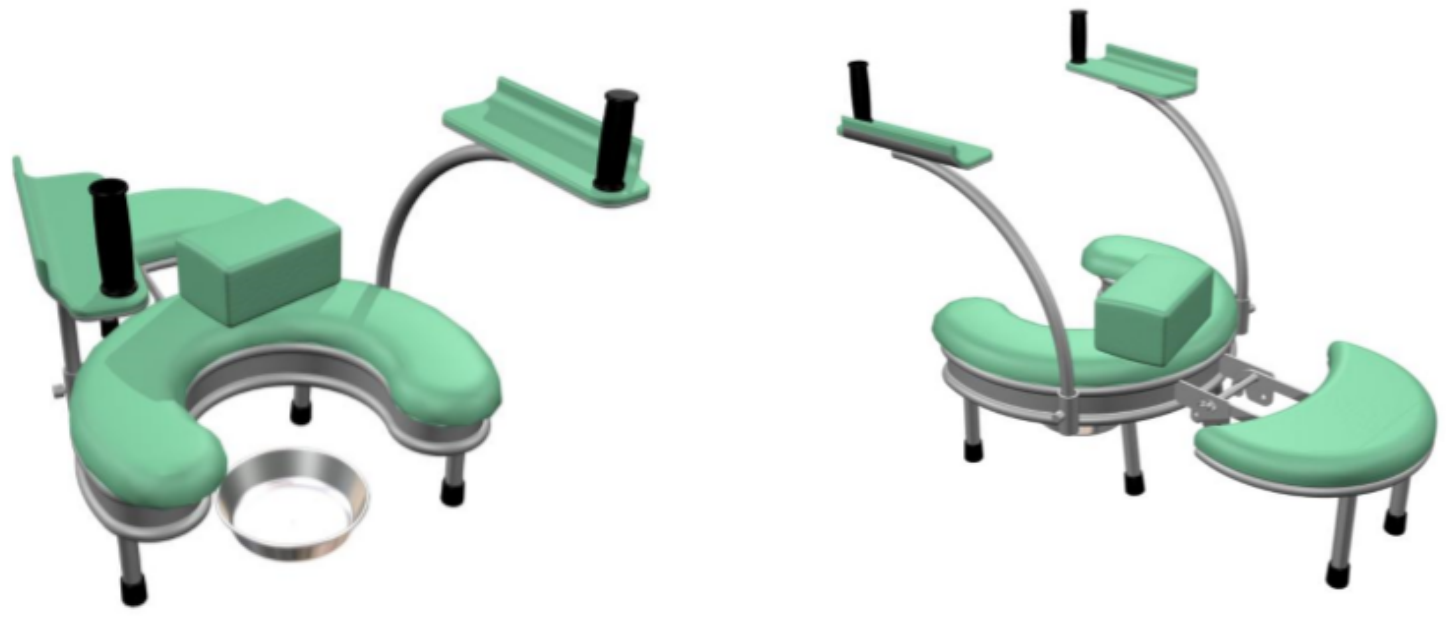

Fonte: autoral (2007)

Vale salientar que para essa percepção de uma nova proposta de produto, foi necessário realizar pesquisas presencias juntamente com equipe multidisciplinar da Maternidade Elpídio de Almeida, na cidade de Campina Grande-PB. Nessa maternidade há um grupo que trabalha com Parto Humanizado, coordenado pela Doutora e obstetra Melânia Maria Ramos de Amorim. Foi confeccionado um protótipo, cedido à maternidade em questão, de modo a validar as pesquisas e verificar a eficácia ergonômica do produto. 


\subsection{Validação da usabilidade da Cadeira $\mathrm{COCH}$}

Para as validações foram feitas entrevistas com mulheres em situações diferenciadas de gestação e de tipos físicos distintos e extremos (figura 8), a fim de perceber se este produto se adequava aos diferentes padrões existentes. Também foi realizado questionário com os médicos, fisioterapeutas, doulas e com os acompanhantes das gestantes, para relato de experiência.

Figura 8: Imagens das variações extremas do corpo humano.

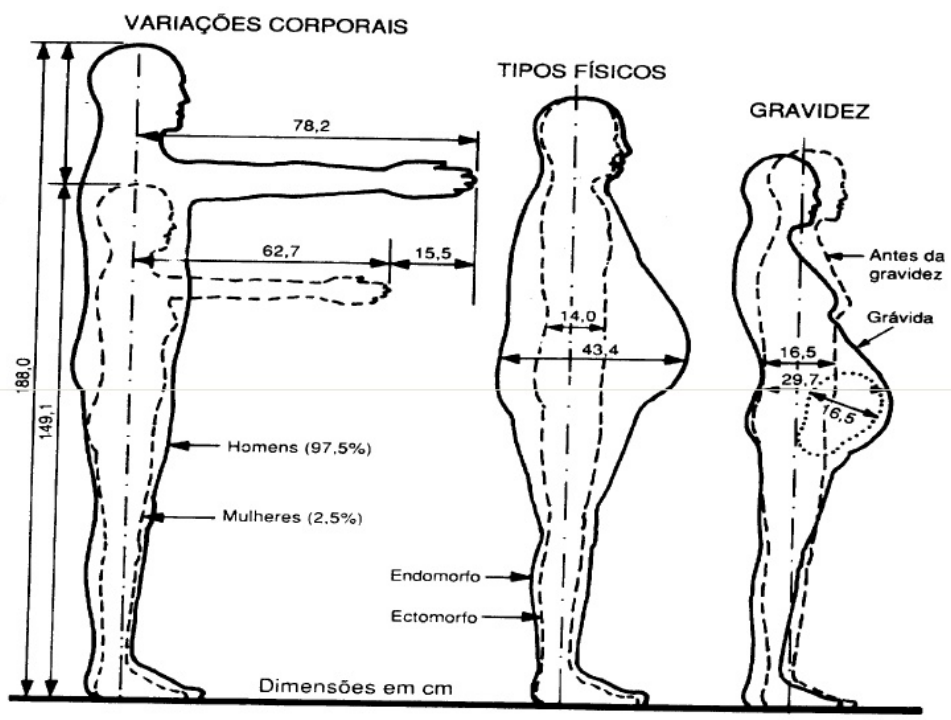

Fonte: Diffrient et al., 1974

Quanto às validações, pôde-se perceber que os braços da cadeira COCH estão numa posição favorável para a paciente exercer a concentração de força necessária para a expulsão do bebê. A maioria das mulheres expressou satisfação com a parte em questão, afirmando que foi de extrema importância em determinados momentos do parto. Algumas pessoas comentaram sobre a possibilidade do braço poder ser articulável, a fim de permitir o uso de maneira mais confortável por pessoas de tipo físico maior (figura 8). Para esse fator ser atendido no projeto, além de sistema articulável, necessitaria de uma trava para garantir a segurança do produto.

Em relação à reclinação do encosto, utilizado também como assento para acompanhante, os entrevistados relataram satisfação quanto a esse item com bastante ênfase. A parte do equipamento se mostrou funcional, tanto para o apoio psicológico do parceiro, doula ou de alguém da estima da paciente, quanto no momento pós-nascimento, para descanso da parturiente e outros procedimentos médicos corriqueiros.

Referente à forma, material e acabamentos escolhidos para o projeto, a resposta dos usuários também foi positiva. Em relação à forma e acabamento, os usuários entenderam que a cadeira $\mathrm{COCH}$ se apresenta melhor do que a banqueta similar, pois permite que elas fiquem mais confortáveis pelo dimensionamento, estofado e tecido adotado. 0 material da estrutura também se apresenta adequado quanto à resistência ao peso, bem como a leveza para transporte de um 
local para outro e no quesito assepsia, por se tratar de aço inoxidável.

Nas validações foi possível observar um inconveniente para os profissionais da saúde (médicos, fisioterapeutas, doulas e pediatras) no que se refere à necessidade de se abaixar ou ficarem sentados no chão, constantemente, para acompanhar a evolução da criança durante o parto verticalizado. A maioria não reclamou desse fator e até expressaram seu contentamento na realização dessas posturas para verem crianças nascendo mais saudáveis, de maneira mais rápida e natural. Entretanto, é papel do designer, observar todos os aspectos do produto, para melhorá-lo, antes de ser comercializado em larga escala.

Segundo a médica Cláudia Bianka Manhães, que faz partos na cadeira $\mathrm{COCH}$ há mais de quatro anos:

"Essa cadeira possibilita a parturiente e ao seu acompanhante uma maneira mais rápida e com menos trauma psicológico e físico, pela própria posição que a gestante fica sentada, bem como pelo auxilio dos sistemas funcionais que a cadeira possui. Permite que ela exerça a força da maneira correta e torna a expulsão do bebê mais rápida e eficiente. Muitas mulheres já conseguiram parir seus filhos em situações complicadas e que a verticalização do parto foi crucial para que não fosse necessária uma intervenção cirúrgica de um parto cesariano. Isso traz mais saúde para a mãe e para o bebê."

Portanto, através das validações desse equipamento, foi possível verificar a eficiência do produto e como ele contribui para a satisfação de seus usuários para um parto mais rápido, com menos dor e menos procedimentos cirúrgicos, sejam esses simples ou complexos.

\section{Considerações Finais}

Ao final desta pesquisa, observou-se que a aplicação dos conceitos da ergonomia é eficaz na identificação de problemas vivenciados em âmbito hospitalar. A realização das visitas in loco, observando a realização das atividades, compreende uma importante ferramenta para diagnosticar e detectar os pontos de fragilidade dos sistemas e dos produtos.

Com base no levantamento realizado foi possível identificar os principais problemas relacionados à má realização das atividades do parto humanizado. Com a verificação dos problemas quanto à ergonomia física, cognitiva e organizacional, buscou-se identificar os possíveis pontos de ação para a minimização dos problemas referente à cadeira para parto de cócoras, posição mais indicada por alguns autores.

Assim, foi apresentada uma solução em forma de protótipo, para a Maternidade Elpídio de Almeida, na cidade de Campina Grande-PB, de modo a observar e validar se a solução proposta seria aceita pelas usuárias. $O$ resultado foi bastante positivo, onde através de entrevistas, tanto com a equipe quanto com as pacientes, foi possível perceber que a cadeira para parto de cócoras $\mathrm{COCH}$ vem facilitando o trabalho de parto. Constatou uma maior rapidez na expulsão do feto e menos necessidades de intervenções cirúrgicas.

Como estudos futuros, estima-se a continuação do projeto, agora com foco maior na ergonomia do médico, de modo que a cadeira possa ter maior usabilidade por ambos os públicos 
alvos. Assim, espera-se que tais estudos venham a promover melhorias na área da Saúde, tanto para os profissionais da saúde quanto para as pacientes, impactando em uma prestação de serviço de melhor qualidade à população.

\section{Referências}

ABERGO. O que é Ergonomia. In: Associação Brasileira de Ergonomia, 2013. (http://www.abergo.org.br/)

ABNT. NBR ISO-9241- Requisitos ergonômicos para trabalho de escritórios com computadoresOrientações sobre Usabilidade. In: Associação Brasileira de Normas e Técnicas, 2011. (http://www.abnt.org.br/)

ACKER, Justina Inês et al. As parteiras e o cuidado com o nascimento. Revista Brasileira de Enfermagem, v. 59, n. 5, 2006.

ADUL, J.; WEERDMEESTER, B. Ergonomia prática. São Paulo: Edgar Blücher, 2004.

BARBOSA, Gisele Peixoto et al. Parto cesáreo: quem o deseja? Em quais circunstâncias? Cadernos de Saúde Pública, v. 19, p. 1611-1620, 2003.

CARDOSO V.; MORAES A. Ergonomia hospitalar: atividades de alimentação e deficiências dos equipamentos disponíveis. In: ENEGEP, 1998.

CARVALHO, I.; CHACHAM,A.; VIANA,P. Parteiras tradicionais e suas práticas na área rural de Pernambuco. Pernambuco 1996.

CYBIS. W.; HOLTZ. A.; FAUST. R. Ergonomia e usabilidade: conhecimentos, métodos e aplicações. São Paulo: Novatec editora, 2010.

DUARTE,A. Tipos de parto. In: Amigas do Parto, 2004. (http://www.amigasdoparto.com.br/)

GARDENAL, I. Técnica de parto alternativo cruza o Atlântico. In: Jornal Unicamp, 2003. (http://www.unicamp.br/unicamp/unicamp_hoje/ju/marco2004/ju245pag04b.html/)

GOMES FILHO, J. Ergonomia do objeto: sistema ténico de leitura ergonômica. São Paulo: Escrituras Editora, 2010.

IIDA, I. Ergonomia: projeto e produção. São Paulo: Edgar Blücher; 2005.

KARWOWSKI, W.; SOARES, M.; STANTON, N. Handbook of Human Factors in Consumer Product Design. Boca Raton, CRC Press, 2011.

LANCET. Caesarean delivery rates and pregnancy outcomes: the 2005 WHO global survey on maternal and perinatal health in Latin America. In: Pub Med, 2007. (http://www.ncbi.nlm.nih.gov/) LIMA, M. Introdução aos materiais e processos para Designers. Rio de Janeiro: Editora Ciência Moderna Ltda., 2006.

MARINHO, A. Abordagem fisioterapêutica no parto de cócoras. Universidade Estadual da Paraíba, 2004. 


\section{Artigo Completo}

MINISTÉRIO DA SAÚDE. Trabalhando com parteiras tradicionais. In: Dicas de Saúde, 2007. (http://portal.saude.gov.br/portal/saude/)

MORAES, A. Ergodesign do ambiente construído e habitado. Rio de Janeiro: IUSER. 2004

OLIVEIRA, I. “Epidemia” do Parto Cesáreo. In: Midial Saúde, 2008. (http://www.medialsaude.com.br).

PHEASANT, S. Bodyspace: anthropometry, ergonomics and the design of work. London: Taylor \& Francis, 2005.

SERRANHEIRA, F.; UVA, A.; SOUSA, P. Ergonomia hospitalar e segurança do doente: mais convergências que divergências. In: Revista Portal Saúde Pública. 2010.

SILVA, A. A Carne Se Faz Verbo: O Parto De Baixo Risco Visto Pela Ótica Das Mulheres. In: Amigas do Parto, 2004. (http://www.amigasdoparto.org.br/) 